\title{
Pemancar dan Penerima FM
}

\author{
Budihardja Murtianta \\ Program Studi Teknik Elektro, \\ Fakultas Teknik Elektronika dan Komputer, \\ Universitas Kristen Satya Wacana, Salatiga \\ budihardja.murtianta@staff.uksw.edu
}

\begin{abstract}
Ringkasan
Pada tulisan ini dirancang dan direalisasikan piranti pemancar dan penerima FM. Pada piranti pemancar dan penerima $F M$, isyarat pembawa bekerja pada frekwensi $88-108 \mathrm{MHz}$ dengan isyarat informasi berupa isyarat sinusoidal dengan frekwensi $10 \mathrm{KHz}$. Bagian pemancar akan memodulasi isyarat informasi dengan isyarat pembawa sehingga dihasilkan isyarat FM. Isyarat FM ini kemudian ditransmisikan secara wireless ke bagian penerima radio $F M$ dengan daya pada penguat $R F \quad 0,8$ Watt. Bagian penerima akan mendemodulasikan isyarat FM menjadi isyarat informasi awal. Dari pengujian yang dilakukan, secara keseluruhan piranti pemancar dan penerima FM yang direalisasikan dapat digunakan untuk mengirimkan dan menerima informasi sesuai yang diharapkan. Akan tetapi isyarat informasi yang diterima pada penerima mengalami gangguan derau yang cukup besar.
\end{abstract}

Kata kunci: pemancar, penerima, modulasi, wireless

\section{Pendahuluan}

Pada sistem telekomonukasi elektrik, pesan atau informasi yang bukan dari besaran listrik diubah dahulu menjadi isyarat listrik dan ditumpangkan pada sebuah isyarat pembawa yang akan menghantarkan pesan tersebut ke tujuan. Isyarat pesan yang telah berubah bentuk menjadi isyarat informasi elektrik ini disebut dengan isyarat pemodulasi.

Guna mendukung proses pengiriman informasi tanpa kabel (wireless), dibutuhkan suatu teknik modulasi analog ataupun digital. Modulasi analog dapat dibedakan menjadi tiga yaitu, modulasi frekwensi, modulasi amplitudo dan modulasi fase. Modulasi frekwensi merupakan sistem modulasi yang mengubah frekwensi isyarat pembawa sebanding dengan amplitudo sesaat isyarat pemodulasi. Berbeda dengan modulasi amplitudo yang amplitudo isyarat pembawanya yang diubah - ubah sebanding dengan amplitudo isyarat informasi, pada modulasi frekwensi, amplitudo dipertahankan tetap. FM (Frequency Modulation) merupakan kasus khusus modulasi sudut (angular modulation). Dalam sistem modulasi sudut, frekwensi gelombang pembawa berubah terhadap waktu menurut fungsi isyarat yang dimodulasikan (ditumpangkan).

\section{Pemancar dan Penerima FM}

Pada bagian ini akan dibahas pengertian - pengertian dan fungsi setiap modul sistem piranti pemancar dan penerima $F M$ yang akan dibangun sesuai dengan perancangan. 


\subsection{Pemancar $F M$}

Pada prinsipnya, sebuah pembangkit gelombang radio (pemancar radio) terdiri dari sebuah osilator radio frekwensi, modulator, penguat daya, jalur transmisi, dan antena. Sistem modulator dan penguat daya pemancar sangat ditentukan oleh jenis modulasi yang digunakan. Bagan kotak pemancar FM ditunjukkan pada Gambar 2.1.

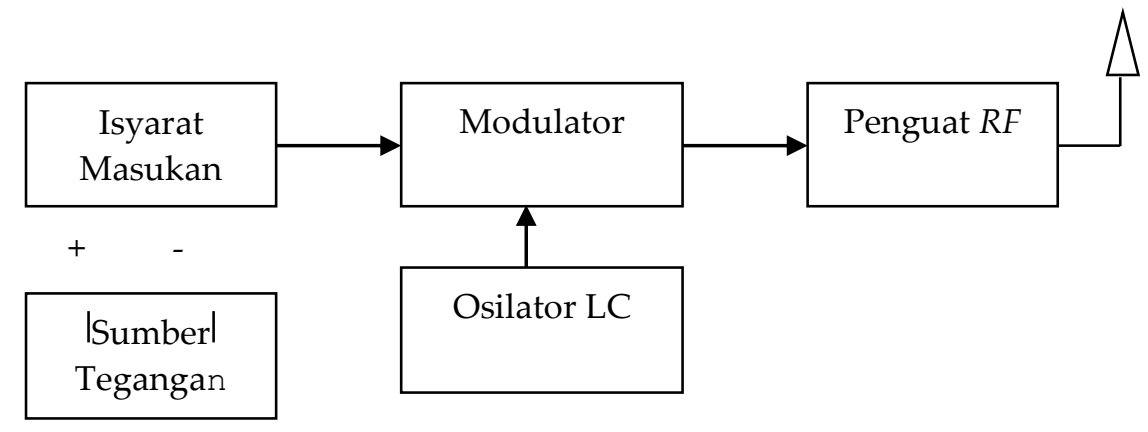

Gambar 2.1. Bagan Kotak Pemancar FM

\subsubsection{Isyarat Masukan}

Isyarat masukan merupakan isyarat informasi yang diubah menjadi isyarat listrik dalam ranah frekwensi yang akan dikirim oleh pemancar, misalnya berupa isyarat audio yang berasal dari luar sistem. Isyarat pesan yang telah berubah bentuk menjadi isyarat informasi elektrik ini disebut dengan isyarat pemodulasi.

\subsubsection{Modulator}

Modulator adalah bagian pengolah isyarat dengan frekwensi informasi ditumpangkan pada frekwensi pembawa yang kemudian disalurkan ke untai penguat dan dipancarkan ke udara melaui antena. Proses modulasi pada gelombang radio adalah proses menumpangkan isyarat informasi ke dalam isyarat pembawa dengan cara - cara modulasi yang digunakan. Tujuannya adalah agar isyarat informasi bisa dikirimkan ke tempat yang jauh. Syarat mutlak yang harus dipenuhi dalam proses modulasi ialah frekwensi isyarat pemodulasi harus lebih rendah dari frekwensi isyarat pembawa. Pada prakteknya, modulator sebuah pemancar bukan merupakan suatu untai tersendiri.

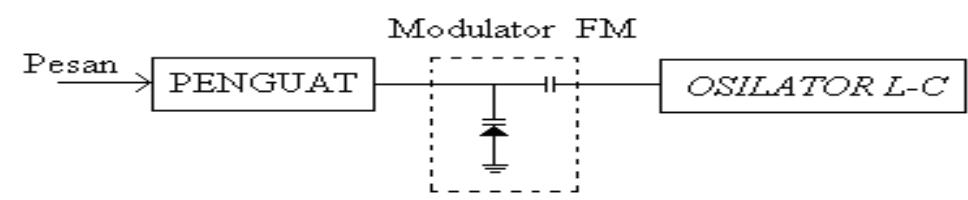

Gambar 2.2. Modulator FM

\subsubsection{Osilator}

Osilator merupakan pembangkit arus rangga dengan amplitudo tetap dengan frekwensi tertentu. Pada dasarnya, osilator adalah sebuah penguat tegangan dengan bati tinggi yang diberi umpan balik (feed-back) positif sehingga penguat menjadi tidak stabil dan berosilasi dengan osilasi tertentu. Agar frekwensi osilasinya dapat diatur dan ditentukan, maka penguat itu dilengkapi dengan resonator. 


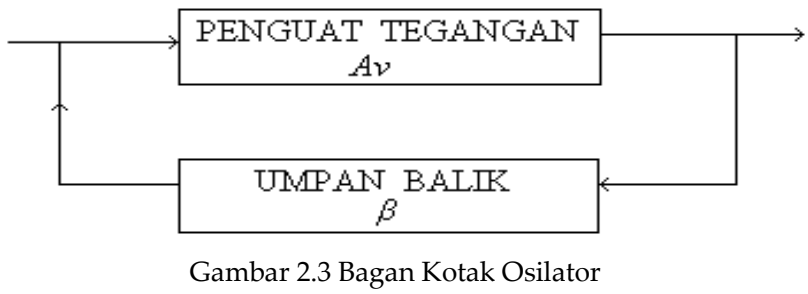

Untai akan berosilasi jika dipenuhi syarat :

$$
\frac{\text { bati simpal }}{\text { untai tertutup(loop gain) }}=1
$$

atau bentuk dalam persamaan :

$$
-\beta A_{v}=1
$$

Syarat ini disebut sebagai kriteria Barkhausen, dan merupakan syarat yang mutlak harus dipenuhi agar sebuah penguat bisa berosilasi secara kontinyu. Apabila bati simpal lebih kecil dari 1 maka kan terjadi osilasi yang semakin lama semakin membesar. Osilator menghasilkan frekwensi pembawa $\left(f_{c}\right)$ yang merupakan frekwensi tinggi, frekwensi pembawa berguna untuk menumpangkan frekwensi informasi $\left(f_{m}\right)$ yang relatif lebih rendah. Osilator yang digunakan untuk untuk frekwensi tinggi umumnya osilator L- C.

\subsubsection{Penguat daya $R F$}

Penguat daya frekwensi radio adalah penguat akhir yang memperkuat isyarat pembawa yang telah termodulasi. Penguat $R F$ berfungsi untuk menapis atau menyaring isyarat - isyarat harmonisa dan isyarat lain yang dihasilkan osilator selain isyarat utama, penguat $R F$ juga berfungsi untuk memperkuat frekwensi pancaran. Penguat $R F$ ini merupakan penguat akhir tertala yang hanya memperkuat satu pita frekwensi tertentu dan meredam pita frekwensi diluarnya. Penguat $R F$ yang digunakan pada pemancar ini ialah penguat $R F$ kelas $C$. Untuk memperkuat gelombang sinus, penguat kelas $C$ harus ditala ke frekwensi gelombang sinus. Karenanya penguat kelas $C$ yang ditala merupakan untai pita arus sempit, penguat kelas $C$ hanya dapat memperkuat frekwensi - frekwensi disekitarnya. Dalam untai kelas C, arus mengalir jauh lebih kecil dari $180^{\circ}$, dan tampak seperti pulsa sempit. Jika pulsa arus sempit seperti ini menggerakan rangkaian resonan, tegangan pada untai penguat hampir medekati gelombang sinus sempurna.

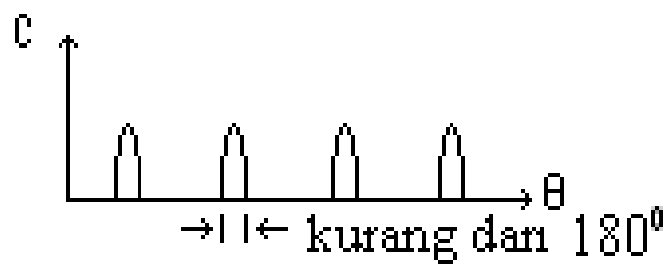

Gambar 2.4. Pulsa Arus Sempit

\subsubsection{Antena}

Antena digunakan untuk memancarkan atau meradiasikan gelombang elektromagnetik ke udara. Agar antena dapat memancarkan isyarat dengan efisien maka panjang antena adalah seperempat panjang gelombang. 


\subsubsection{Sumber Tegangan}

Sumber tegangan merupakan bagian yang memberikan daya listrik kepada bagian bagian pemancar $F M$. Tanpa adanya tenaga listrik maka bagian - bagian pada pemancar $F M$ tidak dapat bekerja. Sumber listrik yang digunakan merupakan sumber tegangan $D C$.

\subsection{Penerima}

Penerima radio $F M$ bertugas menerima isyarat $R F$, memperkuat, mendemodulasikan, dan memperkuat isyarat informasi yang didapat sehingga bisa dimengerti.

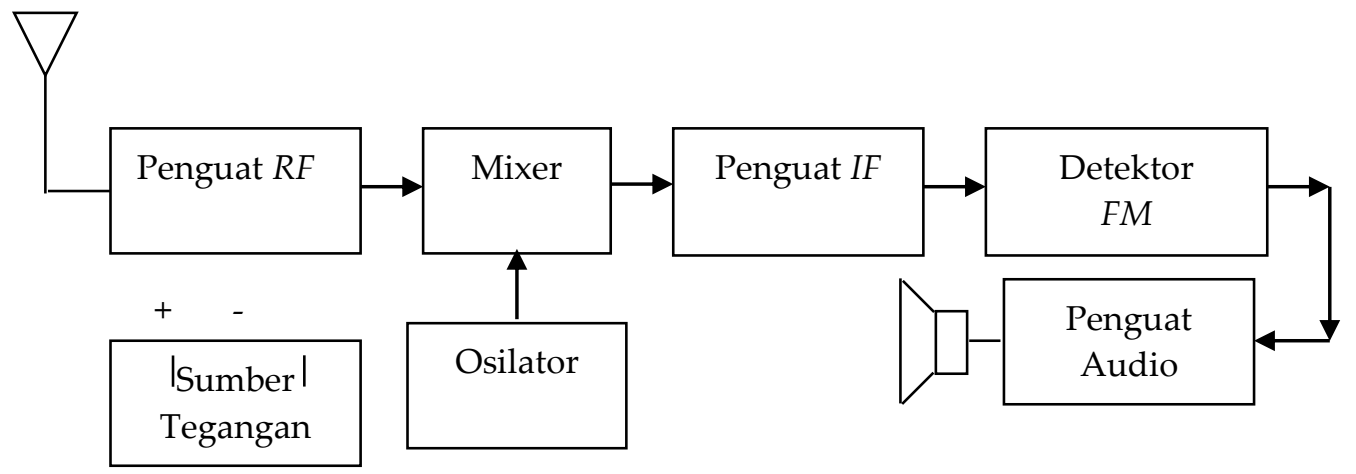

Gambar 2.5 Bagan Kotak Penerima FM

\subsubsection{Antena}

Gelombang elektromagnetik di udara ditangkap oleh antena yang berguna sebagai peranti untuk menangkap pancaran gelombang elektromagnetik, kemudian diubah menjadi isyarat listrik.

\subsubsection{Penguat $R F$}

Untuk meningkatkan unjuk kerja radio penerima $F M$, isyarat pembawa $\left(f_{c}\right)$ perlu dikuatkan pada penguat $R F$. Penguat $R F$ merupakan penguat yang bersifat penapis. Penguat $R F$ digunakan untuk memilah isyarat pada penala sehingga dapat mencegah masuknya frekwensi lain yang masuk pada untai pencampur yang dapat menimbulkan frekwensi bayangan dan meningkatkan unjuk kerja radio penerima $F M$

\subsubsection{Mixer}

Mixer atau pencampur merupakan tempat pencampuran antara frekwensi yang berasal dari penguat $R F\left(f_{c}\right)$ dengan frekwensi yang dihasilkan osilator $\left(f_{o}\right)$. Keluarannya setelah ditapis adalah sebuah isyarat berfrekwensi $\left(f_{o}-f_{c}\right)$. Isyarat ini lazim disebut dengan isyarat frekwensi-menengah (intermediate-frequency, IF). Pada pencampur ini akan dihasilkan frekwensi menengah $10.7 \mathrm{MHz}$.

\subsubsection{Osilator}

Merupakan pembangkit isyarat elektrik arus rangga dengan amplitudo tetap dan frekwensi $\left(f_{o}\right)$ yang akan dicampurkan dengan isyarat masukan $\left(f_{c}\right)$ pada pencampur. Karena perubahan frekwensi penalaan di bagian penguat $R F$ dibuat sama dengan perubahan frekwensi penalaan osilator lokal, maka hasil pencampuran antara frekwensi 
osilator $\left(f_{o}\right)$ dan frekwensi pembawa $\left(f_{c}\right)$ yang dikuatkan pengut IF memiliki frekwensi yang tetap, yang secara praktis nilainya sekitar 10,7 MHz

\subsubsection{Penguat IF}

Penguat IF disebut juga penguat frekwensi menengah. Hasil pencampuran getaran listrik dari lingkaran penala yang telah dicampur pada bagian mixer, yang merupakan frekwensi menengah ini masih lemah oleh karena itu harus diperkuat pada penguat $I F$.

\subsubsection{Detektor}

Untuk dapat mendeteksi suatu isyarat maka diperlukan suatu untai yang tegangan keluaranya linear sesuai dengan frekwensi isyarat masukan. Pada bagian penguat IF dan transformator $M F$ masih tercampur antara frekwensi tinggi $\left(f_{c}\right)$ dan frekwensi informasi . Jika keduanya tidak dibedakan maka kita tidak dapat mendengarkan suara dari radio sehingga diperlukan detektor untuk memisahkan antara frekwensi pembawa $\left(f_{c}\right)$ dan frekwensi suara $\left(f_{m}\right)$.

\subsubsection{Penguat Audio}

Oleh karena untuk mengeluarkan suara loudspeaker memerlukan tenaga atau aliran listrik yang cukup, maka itu frekwensi isyarat suara harus dikuatkan pada penguat audio sehingga amplitudo isyarat suara tersebut dapat menggerakkan membran penyuara.

\subsubsection{Sumber Tegangan}

Sumber tegangan merupakan bagian yang meberikan daya listrik kepada bagian bagian penerima FM. Tanpa adanya tenaga listrik maka bagian - bagian pada penerima $F M$ tidak dapat bekerja. Sumber listrik yang digunakan merupakan sumber tegangan $D C$.

\section{Perancangan Untai Pemancar dan Penerima FM}

Sistem yang digunakan untuk merealisasikan piranti telah dijelaskan pada tulisan di atas, sedangkan pada bagian ini akan dibahas mengenai perancangan alat yang dilakukan untuk merealisasikan sistem piranti pemancar dan penerima $F M$.

\subsection{Pemancar $F M$}

Dalam mengirimkan informasi jarak jauh diperlukan pemancar. Pada piranti pemancar FM sederhana ini terdapat bagian - bagian yang akan dijelaskan sebagai berikut.

\subsubsection{Pembangkit Isyarat Informasi}

Isyarat informasi pada piranti yang dirancang ini berupa isyarat sinusoidal. Perancangan pembangkit isyarat sinusoidal menggunakan IC monolith function generator $X R 20206$ yang selain dapat membangkitkan isyarat sinusoidal juga dapat membangkitkan isyarat gelombang segitiga dan gergaji. IC XR 2206 terdiri 16 pin, untuk mengatur frekwensi pembangkit isyarat sinus di tentukan oleh pin 5 dan 6 pada IC XR 2206 dan nilai resistor pin 7 dan ground. Nilai frekwensi dapat dihitung dengan persamaan berikut : 


$$
f=\frac{1}{2 \pi \cdot R \cdot C}
$$

$f=$ frekwensi;

$\mathrm{C}=\quad$ kapasitor pada pin 5 dan 6; dan

$\mathrm{R}=$ resistor yang terpasang pada pin 7 .

Spesifikasi piranti yang dirancang menggunakan gelombang sinusoidal dengan frekwensi $10 \mathrm{KHz}$, yang direalisasikan dengan menetapkan nilai kapasitor yaitu 10nF.

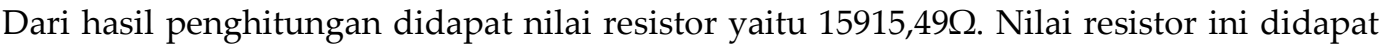
dengan menggunkan variable resistor. Amplitudo pada keluaran sinusoidal diatur dengan mengubah - ubah nilai resistor pin 3. Untuk mengatur kesimetrisan gelombang sinusoidal pada keluaran, dilakukan dengan mengubah - ubah nilai resistor yang terpasang pada pin 15 dan 16. Bentuk gelombang diatur pada resistor pin 13 dan 14 .

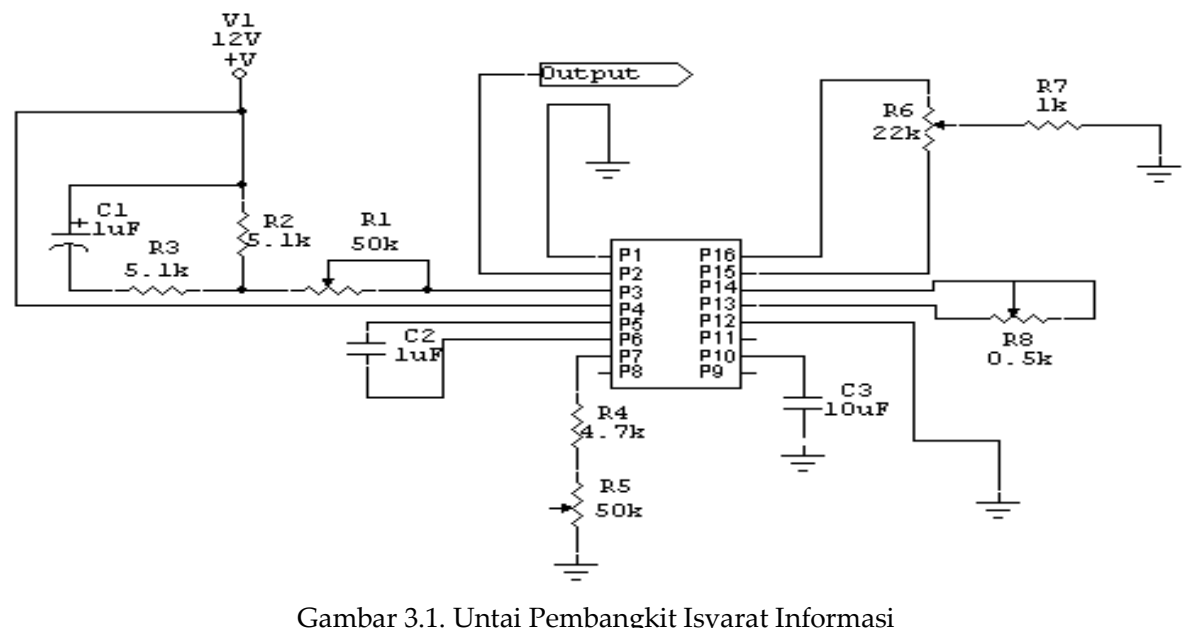

\subsubsection{Modulator}

Modulator untuk menumpangkan isyarat informasi ke dalam isyarat pembawa. Syarat mutlak yang harus dipenuhi agar proses modulasi dapat dilakukan yakni frekwensi isyarat pemodulasi harus lebih rendah daripada frekwensi isyarat pembawa. Perancangan ini menggunakan modulasi aras rendah dengan memodulasikan isyarat informasi di tingkat - tingkat awal penguat untai pemancar. Modulator FM ini menyatu dengan untai pemancar.

\subsubsection{Osilator}

Osilator merupakan bagian pemancar FM dimana isyarat pembawa dibangkitkan. Osilator sendiri pada dasarnya terdiri dari dua bagian yaitu penguat dan untai umpan balik. Salah satu frekwensi yang dihasilkan tersebut akan menjangkitkan umpan balik dengan fase yang benar $\left(0^{0}\right)$. Sedangkan penguat akan menghasilkan isyarat keluaran yang telah dikuatkan beberapa kali. Osilator yang digunakan pada perancangan ini berupa osilator LC colpitts. Perancangan osilator menggunakan VFO (Variable Frequency Oscilator) yang merupakan modifikasi osilator colpitts yang dapat membangkitkan isyarat pembawa dengan frekwensi $88 \mathrm{MHz}$ - $108 \mathrm{MHz}$. Dengan demikian dibutuhkan untai dengan komponen - komponen kapasitor dan induktor yang dapat berosilasi dari $88 \mathrm{MHz}-108 \mathrm{MHz}$. 


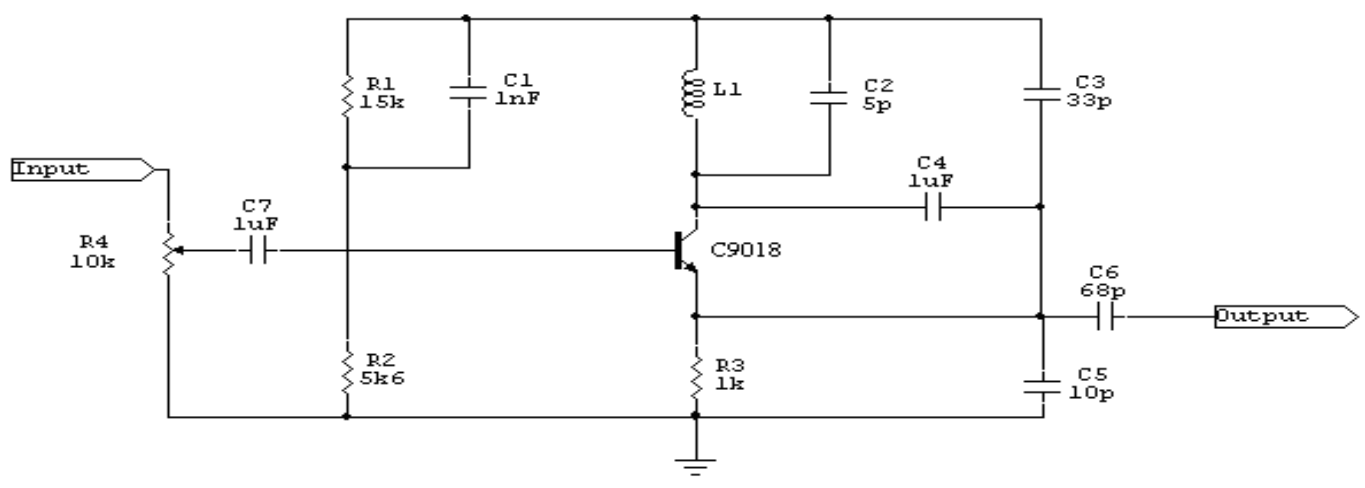

Gambar 3.2. Untai Osilator

Penentu frekwensi yang dibangkitkan pada osilator ini adalah nilai L1 dan C2 yang memiliki hubungan matematis sebagai berikut.

$$
f \cong \frac{1}{2 \pi \sqrt{L C}}
$$

Nilai kapasitor C2 ditetapkan sebesar 5pF dan nilai induktor bisa diubah - ubah. Untuk mendapatkan nilai induktor yang dapat diubah - ubah digunakan koker dengan inti batang ferit $4 \mathrm{~mm}$ yang dililiti oleh kawat email dengan diameter $0,8 \mathrm{~mm}$. Inti ferit dapat diputar sehingga impendasi induktor berubah - ubah dan menghasilkan frekwensi pembawa yang diinginkan. Diameter koker dan jumlah lilitan kawat email sangat berpengaruh terhadap isyarat yang dibangkitkan. Nilai induktor dapat dihitung dengan menggunakan Persamaan (3.2) dengan nilai kapasitor dan frekwensi pembawa yang diketahui.

\subsubsection{Penguat $R F$}

Isyarat hasil pemodulasian perlu dikuatkan, sehingga diperlukan sebuah penguat $R F$. Penguat $R F$ yang digunakan dalam perancangan ini adalah penguat $R F$ kelas $C$ dengan daya Output 1 Watt. Untai pada Gambar 3.3 mempunyai output 1 Watt dengan persamaan sebagai berikut.

$$
P_{o-m a k s}=\frac{V c c^{2}}{2 \cdot z_{c}}
$$

$$
\begin{array}{lll}
P_{o-m a k k s} & : & \text { daya keluaran maksimum (Watt) } \\
V_{c c} & : & \text { tegangan pada kolektor }(\mathrm{V}) \\
z_{c} & : & \text { impendasi C1 dan L1 }
\end{array}
$$




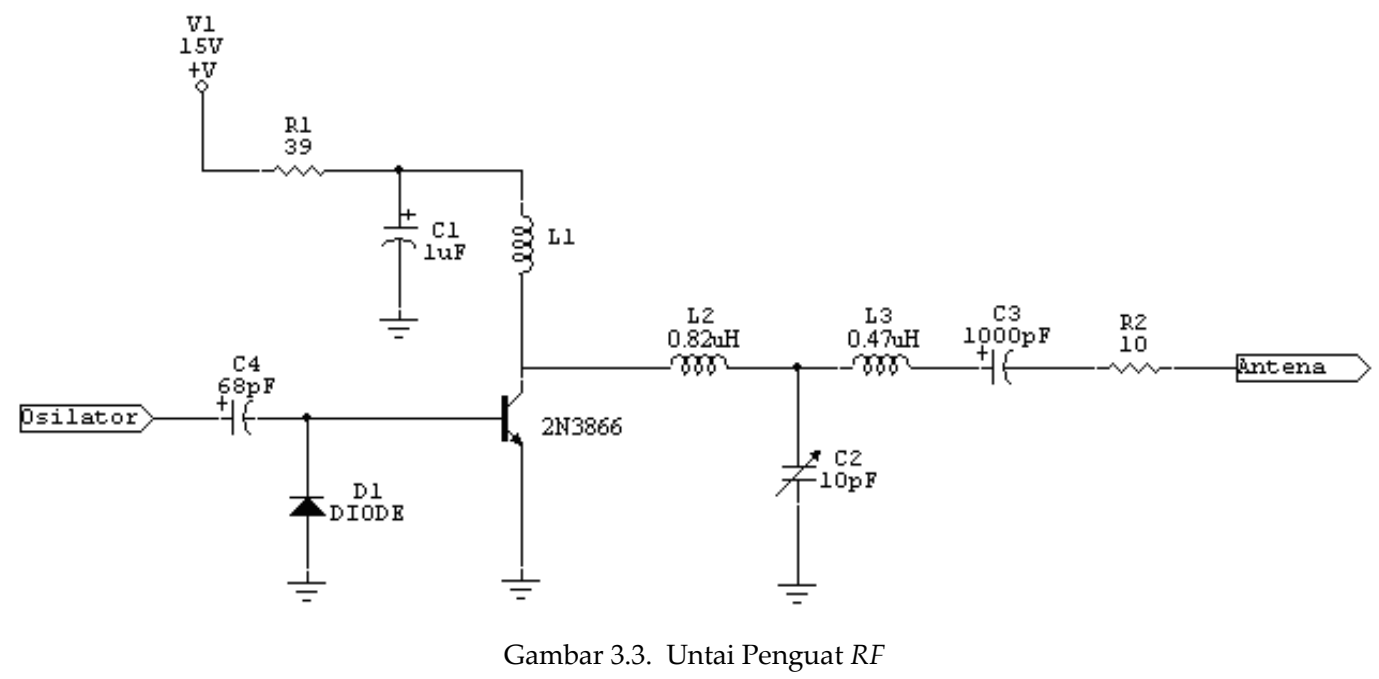

Pulsa arus kolektor pada penguat kelas C yang mengalir kurang dari $180^{\circ}$.Jika pulsa arus sempit menggerakkan untai resonansi yang terdiri dari $C_{2}$ dan $L_{1}$, akan dihasilkan gelombang sinus dari tegangan yang hampir sempurna. Untuk memdapatkan gelombang sinus dengan frekwensi dasar, frekwensi resonansi pada penguat RF harus sama dengan frekwensi dasar gelombang yang dipulsakan. Pada untai penguat $R F$ ini menggunakan induktor berupa gulungan kawat email dengan nilai induktansi $1 \mu \mathrm{H}$.

\subsubsection{Antena}

Pada pemancar, antenna berungsi sebagai peranti yang memancarkan gelombang elektomaknet. Antena akan dapat bekerja efektif jika dimensi dari antena sama dengan panjang isyarat yang hendak dipancarkan. Antena akan meradiasikan gelombang elektromagnetik secara maksimal jika panjang fisik antenna sebesar seperempat panjang gelombang $(1 / 4 \lambda)$ elektromagnetik yang dipancarkan. Pada perancangan ini antena yang digunakan adalah antena vertikal.

\subsubsection{Sumber Tegangan}

Sumber tegangan merupakan bagian yang meberikan energi listrik kepada bagian bagian pemancar $F M$. Tanpa adanya tenaga listrik maka bagian - bagian pada penerima FM tidak dapat bekerja. Sumber listrik yang digunakan merupakan sumber tegangan sebesar $12 \mathrm{VDC}$.

\subsection{Penerima $F M$}

Penerima $F M$ terdiri dari antena, penguat $R F$, pencampur, osilator, penguat $I F$, detektor, penguat audio dan penyuara. Pada beberapa bagian perancangan penerima ini digunakan penala $F M$ yang banyak di pasaran.

\subsubsection{Antena}

Antena yang digunakan dalam perancangan ini adalah antena teleskopik. Panjang antena ini dapat diatur. Agar dapat bekerja maksimal antena diatur panjangnya yaitu sebesar seperempat panjang gelombang. 


\subsubsection{Penguat $R F$, Pencampur, Osilator, dan Penguat $I F$}

Pada penerima $F M$ ini digunakan penala $F M$ yang didalamnya telah terdapat penguat $R F$, pencampur, osilator, dan penguat $I F$. Penala $F M$ yang digunakan memiliki 6 pin. Pin pertama berfungsi sebagai masukan isyarat elektromagnetik yang ditangkap antena. Pin kedua sebagai masukan tegangan penala FM. Untuk dapat bekerja, penala FM membutuhkan tegangan masukan sebesar 9-12 VDC. Pin ketiga berfungsi sebagai keluaran penguat IF. Penguat IF berupa sebuah komponen transformator berfungsi sebagai penguat frekwensi menengah yang pada penerima $F M$ nilainya adalah 10,7 MHz. Transformator frekwensi dapat bekerja apabila frekwensi yang diterimanya sebesar 10,7 MHz. Pin keempat pada penala FM berfungsi sebagai ground. Pin kelima untuk keluaran osilator dan pin keenam untuk keluaran penguat.

\subsubsection{Detektor}

Detektor berfungsi untuk memisahkan getaran frekwensi isyarat pembawa dan frekwensi isyarat informasi. Dalam perancangan detektor digunakan IC monolith LA 1260 yang terdiri dari $16 \mathrm{pin}$. Pin pertama sebagai masukan penguat IF yang terlebih dahulu ditapis pada tapis pada 10,7MHz. Pin kedua dan ketiga berfungsi sebagai bypass. Pin keempat merupakan ground dan pin 7 adalah keluaran yang dikuatkan oleh transistor C828. Piranti detektor pada penerima dapat dilihat pada Gambar 3.4.

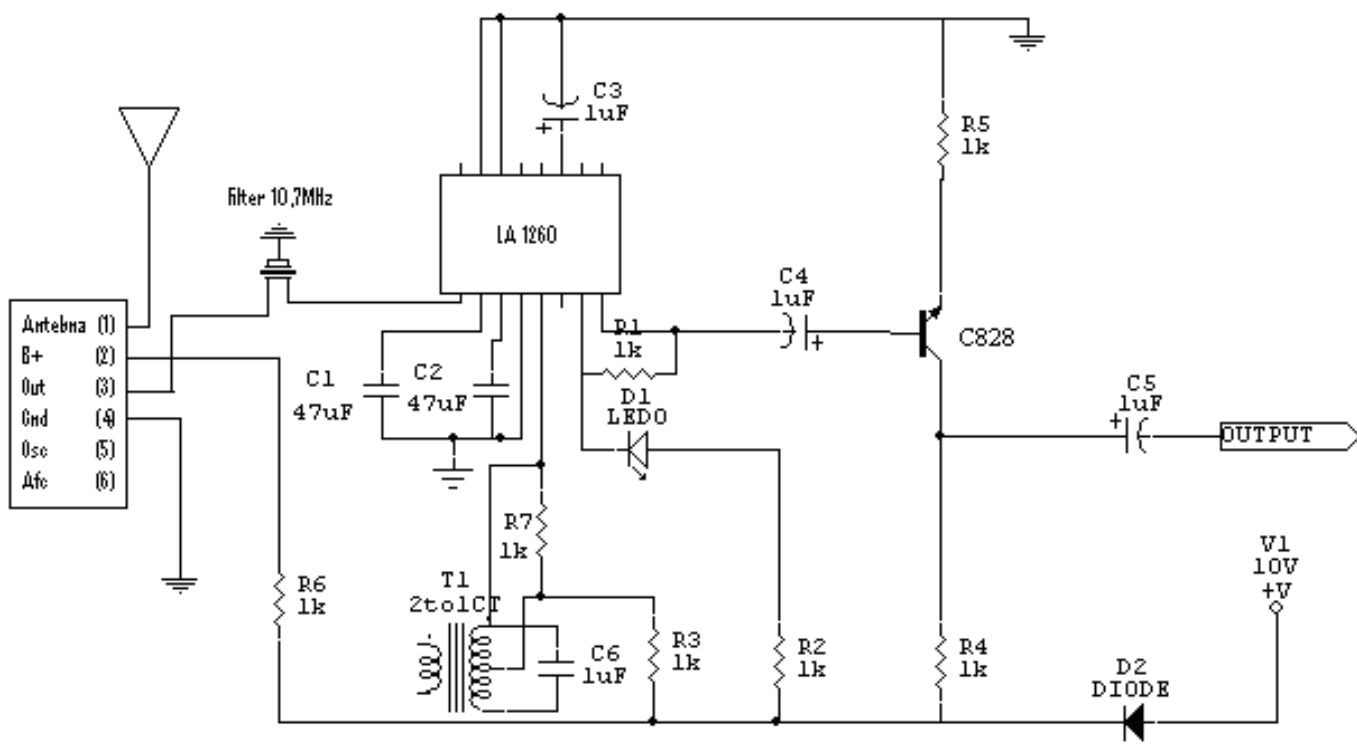

Gambar 3.4. Untai Penerima FM

\subsubsection{Penguat Audio}

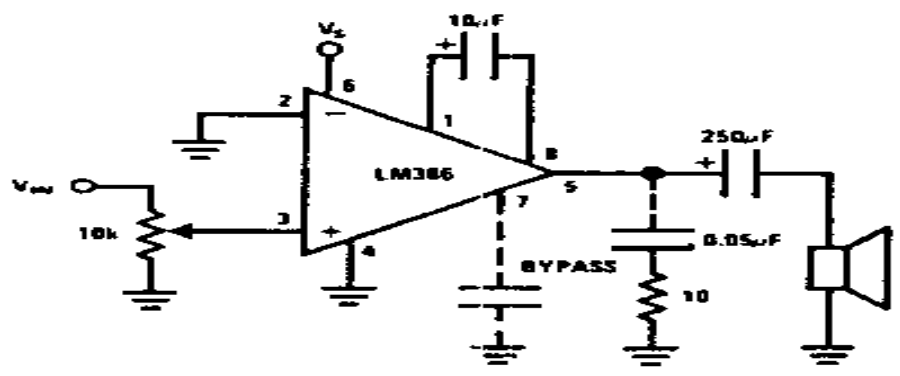

Gambar 3.5. Untai Penguat Audio 
Penguat audio yang digunakan seperti pada Gambar 3.5, adalah penguat audio dengan IC LM 386 yang merupakan penguat daya audio bertegangan kecil. Dari datasheet komponen diketahui penguat audio ini dapat meningkatkan bati dari 20 sampai 200 kali dengan menambahkan komponen resistor atau kapasitor antara pin 1 dan 8 .

\subsubsection{Sumber Tegangan}

Sumber tegangan pada penerima $F M$ merupakan bagian yang meberikan energi listrik kepada penerima FM. Sumber listrik yang digunakan merupakan sumber tegangan sebesar 9-12 VDC.

\section{Pengujian Piranti}

\subsection{Pemancar $F M$}

\subsubsection{Isyarat Pembangkit informasi}

Dari Gambar 4.1 dapat dilihat bahwa pembangkit isyarat sinus dapat membangkitkan isyarat sinus dengan frekwensi $10 \mathrm{KHz}$ dengan amplitudo $2 \mathrm{Vpp}$.

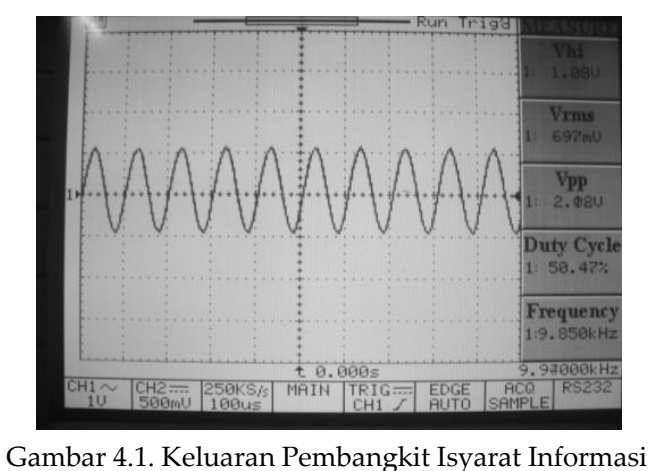

\subsubsection{Isyarat Keluaran Osilator}

Pengujian osilator pada pemancar $F M$ dilakukan dengan mengubah - ubah nilai induktansi induktor osilator. Perubahan nilai induktansi ini berpengaruh terhadap nilai frekwensi yang dihasilkan osilator. Induktor pada osilator berupa koker dengan inti ferit yang dililiti kawat email. Dari hasil penalaan osilator, didapat frekwensi yang dapat dihasilkan yaitu $88-108 \mathrm{MHz}$. Isyarat sinus yang dihasilkan cukup baik dengan kisaran amplitudo $100 \mathrm{mV}$ seperti yang disajikan pada Gambar 4.2 dan 4.3 .

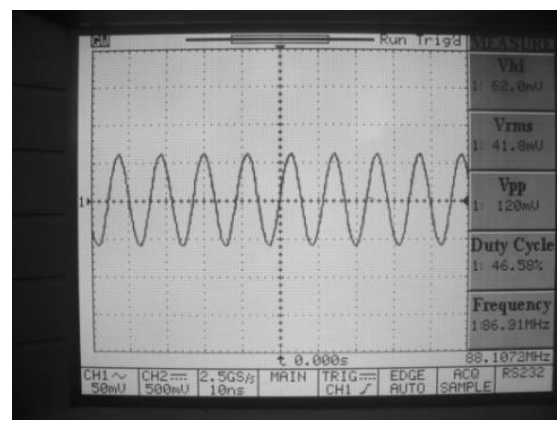

Gambar 4.2. Isyarat Osilator Frekwensi $88 \mathrm{MHz}$ 


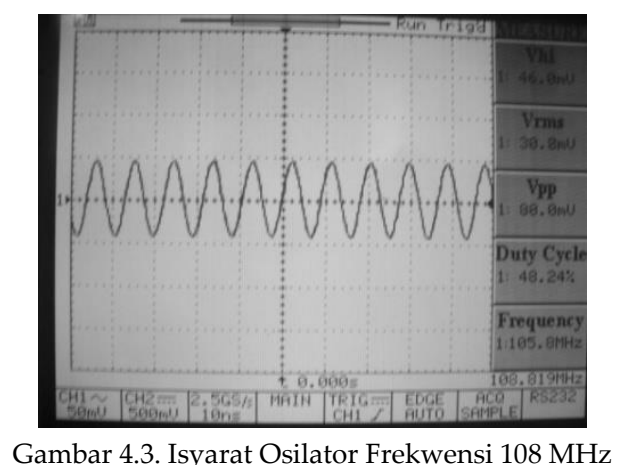

\subsubsection{Isyarat Keluaran Modulator}

Dalam pengukuran, modulator merupakan tempat isyarat informasi ditumpangkan pada isyarat pembawa. Pada pengukuran ditentukan frekwensi isyarat pembawa sebesar $100 \mathrm{MHz}$ dengan frekwensi isyarat informasi sebesar $10 \mathrm{KHz}$ yang beramplitudo 2Vpp. Pada Gambar 4.4, rapat - renggang frekwensi osilasi yang menjadi ciri modulasi FM tidak begitu terlihat dengan jelas. Ini terjadi karena kurangnya sensifitas dan ralat alat ukur pada frekwensi tinggi.

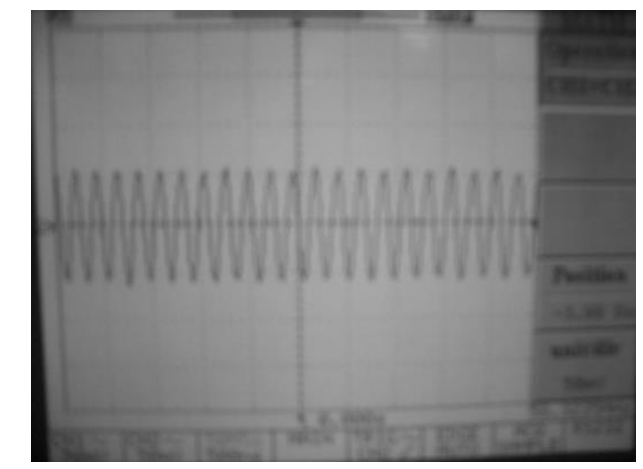

Gambar 4.4. Modulasi fc 100MHz \& Amplitudo 100mV

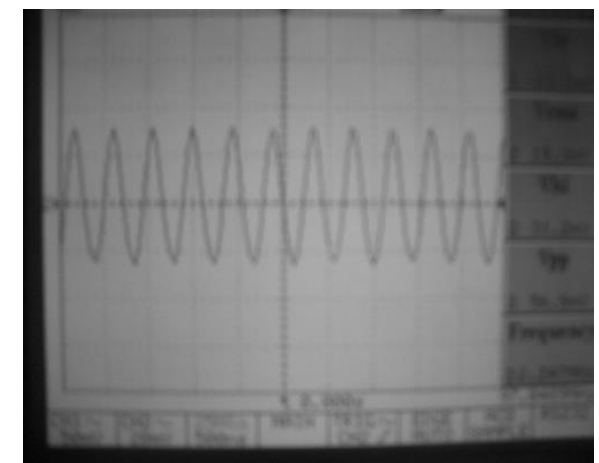

Gambar 4.5. Isyarat Keluaran Penguat RF Pemancar

\subsubsection{Isyarat Penguat $R F$}

Pengukuran dan pengujian penguat $R F$ dilakukan menggunakan spectrum analizer dan meter daya. Untuk membedakan isyarat keluaran modulator dan penguat $R F$ digunakan spectrum analizer. Untuk mengukur daya yang dipancarkan oleh penguat $R F$ digunakan meter daya yang dibebani dummy load. Pada hasil pengukuran penguat $R F$, amplitudo isyarat keluaran pada penguat $R F$ jauh lebih besar dibanding dengan keluaran isyarat modulator karena adanya penguatan. Pada pengukuran menggunakan 
meter daya, penguat $R F$ dihubungkan dengan meter daya yang dibebani dummy load. Hasil pengukuran penguat $R F$ disajikan pada Gambar 4.5. dan daya yang dihasilkan 0,8 Watt.

\subsection{Penerima $F M$}

\subsubsection{Isyarat Keluaran Osilator Penerima}

Isyarat pada osilator penerima pada Gambar 4.6 berfrekwensi 111,3 $\mathrm{MHz}$ dengan amplitudo $121 \mathrm{mVpp}$. Osilator yang ada pada penala $F M$ membangkitkan isyarat sinus dengan frekwensi 111,3 MHz. Secara teori osilator akan menghasilkan frekwensi fo yang bila dicampur dengan frekwensi pembawa $f_{\mathcal{C}}$ pada pencampur akan mengasilkan frekwensi menegah (intermediate-frequency, IF). Jika frekwensi isyarat pembawa yang ditentukan $100 \mathrm{MHz}$ dan frekwensi menegah pada $F M$ lazimnya adalah 10,7 MHz, maka seharusnya osilator menghasilkan frekwensi $110,7 \mathrm{MHz}$ tetapi pada kenyataan pada pengukuran meleset 0,6 MHz. Hal ini terjadi karena adanya ralat komponen dan ralat alat ukur.

\subsubsection{Isyarat Keluaran Penguat IF}

Gambar 4.7 menunjukan keluaran IF penerima pada frekwensi 9,2MHz dengan amplitudo $260 \mathrm{mVpp}$. Isyarat keluaran IF merupakan hasil pencampuran antara isyarat osilator lokal $f_{0}$ pada penala dengan isyarat masukan $f_{\mathcal{C}}$. Isyarat ini lazim disebut frekwensi-menengah. Karena perubahan penalaan di bagian penguat $R F$ dibuat sama dengan perubahan frekwensi penalaan osilator lokal, maka hasil keluaran isyarat IF akan memiliki frekwensi yang tetap di sekitar 10,7 MHz. Dari hasil pengukuran keluaran IF penerima adalah 9,2 $\mathrm{MHz}$ sedikit berbeda dari teori yang seharusnya 10,7 MHz. Hal ini terjadi karena ralat alat ukur dan ralat komponen yang digunakan.

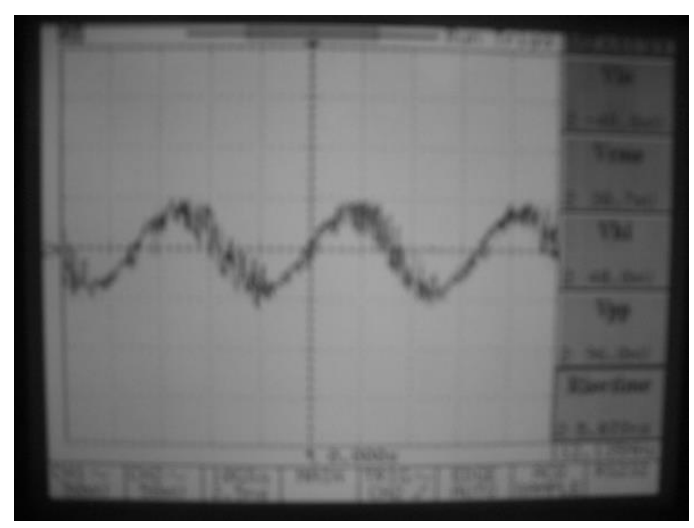

Gambar 4.6. Isyarat Keluaran Osilator Penerima 


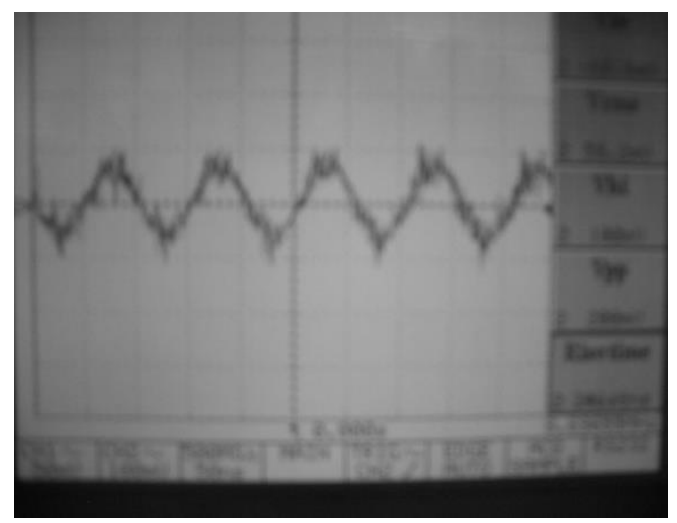

Gambar 4.7. Isyarat Keluaran Penguat IF

\subsubsection{Isyarat Keluaran Detektor}

Detektor berfungsi untuk memisahkan isyarat pembawa dengan isyarat informasi. Pada tahap ini isyarat pembawa akan ditapis sehingga hanya tertinggal isyarat informasi. Isyarat keluaran detektor pada peenerima FM disajikan pada Gambar 4.8.

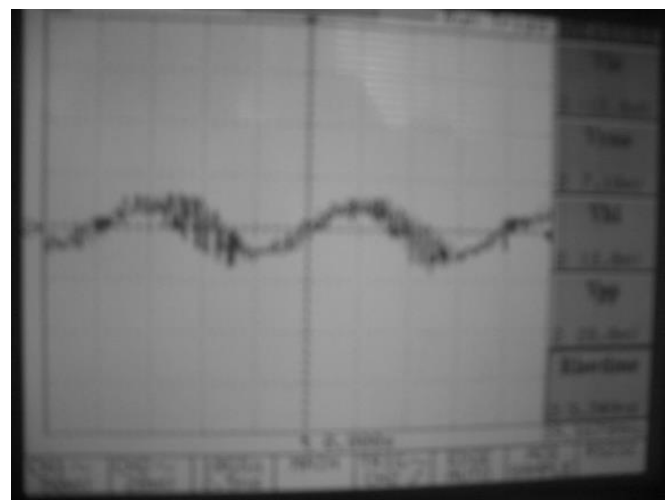

Gambar 4.8. Isyarat Keluaran Detektor

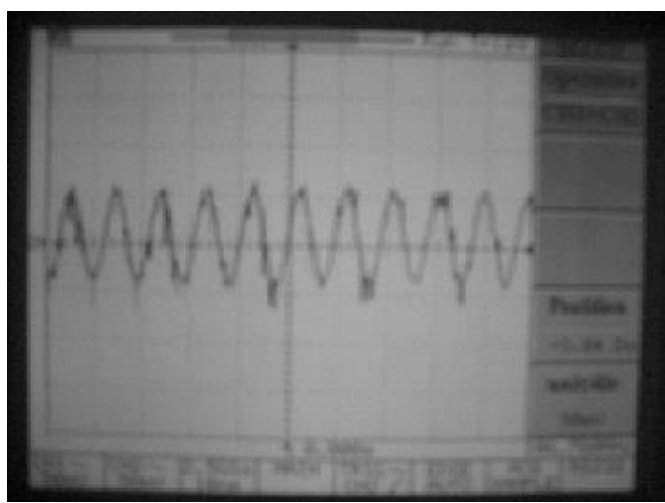

Gambar 4.9. Isyarat Keluaran Penguat Audio

\subsubsection{Isyarat Keluaran Penguat Audio.}

Isyarat pada keluaran penguat audio merupakan penguatan amplitudo isyarat keluaran untai detektor. Pada penguat ini amplitudo isyarat informasi $\left(f_{m}\right)$ dikuatkan beberapa kali sehingga dapat menggerakkan membran penyuara. Pada Gambar 4.9, isyarat sinus yang dihasilkan tidak begitu sempurna. Tampak adanya derau yang terdengar sebagai desis jika penguat audio ini dihubungkan dengan penyuara. 


\section{Kesimpulan}

1. IC monolith function generator XR2206 dapat digunakan sebagai pembangkit gelombang sinus yang baik, stabil.

2. Osilator pada pemacar $F M$, dapat menghasilkan isyarat dengan frekwensi 88-108 $\mathrm{MHz}$.

3. Penguat $R F$ kelas $C$ yang digunakan dapat memancarkan daya 0.8 Watt.

4. Pada pancaran isyarat pembawa $100 \mathrm{MHz}$ osilator penerima bekerja pada frekwensi 111,3 MHz

5. Derau pada penerima cukup besar, sehingga berpotensi mengganggu isyarat informasi.

\section{Daftar Pustaka}

[1] Malvino, Albert Paul, "Prinsip - Prinsip Elektronik", Edisi ke-2, Jakarta Erlangga, 1989

[2] S., Wasito, "Vademekum Elektronika" Edisi ke-2, Jakarta Gramedia Pusataka Utama, 2001

[3] Rappaport, Theodore. S, "Wireless Communication System" $2^{\text {nd }}$ Edition, Upper Saddle River, Prentice-Hall, 2002. 